Tempo Social; Rev. Sociol. USP, S. Paulo, 12(1): 123-140, maio de 2000.

\title{
A questão da universidade e da formação em ciências sociais
}

\author{
SYLVIA GEMIGNANI GARCIA
}

RESUMO: A análise histórica dos processos sociais e intelectuais que caracterizam a formação cultural e científica na modernidade contemporânea permite a reconstrução de questões culturais e educacionais que se fazem constantemente presentes hoje no dia-a-dia da vida universitária na forma de problemas acadêmicos e administrativos. Situada na intersecção das áreas de história intelectual, sociologia da ciência e das instituições científicas e sociologia da educação e da cultura, essa perspectiva de investigação aborda, primeiro, os amplos processos institucionais - nas esferas da política, da economia e da cultura - que situam a questão contemporânea da universidade e da formação em ciências sociais; em seguida, expõe alguns aspectos centrais do debate sociológico acerca da natureza da disciplina e do perfil da formação em ciência social; e, finalmente, discute certos pressupostos e categorias básicas das atuais propostas de reforma universitária.

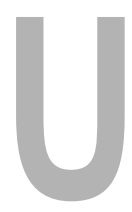

m dos componentes importantes da questão da universidade hoje é a crise da universidade pública. O modo mais disseminado de caracterizar essa crise é considerá-la conseqüência da crise do déficit público dos anos 70 que determinou a falência do sistema de financiamento da rede pública de ensino superior. Nesse diagnóstico estão, portanto, implícitas: a) a atual reestruturação do modo capitalista de produção; e b) a forma mais recente da crise da esfera pública na modernidade contemporânea.

a) De certa perspectiva da análise sociológica, as mudanças sociais contemporâneas vinculam-se a uma reestruturação do modo capitalista de produção a partir da revolução tecnológica da década de 70 baseada, essencialmen-

UNITERMOS: universidade, ciências sociais, sociologia da educação.

Professora do Departamento de Sociologia da FFLCH - USP 
te, em tecnologia informacional. Apropriado pelo sistema econômico, o aparato tecnológico torna possível uma nova forma de interdependência econômica global, acompanhada de uma nova divisão internacional do trabalho, e a unificação internacional dos mercados financeiros. Trata-se de um processo histórico contraditório de extraordinário desenvolvimento de forças produtivas liberadas pela revolução informacional que se realiza aprofundando o caráter desigual das relações de produção através da redefinição dos segmentos e territórios sociais considerados dinâmicos conforme a lógica do sistema econômico e dos outros segmentos, cuja tendência é que não sejam pertinentes da perspectiva da lógica do sistema (cf. Castells, 1999). Em termos amplos, constituem-se processos simultâneos e entrelaçados de unificação e pulverização social por meio de novos modos de inserção e de exclusão social e de formação de novos blocos geopolíticos e geo-econômicos com a paralela destruição de tipos de identidades coletivas que tiveram papel fundamental na história da modernidade tal como se desenvolveu nos últimos séculos, entre as quais destaca-se a identidade nacional vinculada à forma do estado nacional moderno.

O predomínio do capital financeiro sobre o capital industrial e a apropriação tecnológica que o capital realiza produzem uma profunda reestruturação do trabalho e do mercado de trabalho, basicamente caracterizada por tendências a complexificação e diferenciação, desregulamentação e individualização. A desregulamentação refere-se aos novos contratos de trabalho, marcados pela flexibilização e a individualização, com efeitos que variam conforme os setores altamente diferenciados entre si em relação ao seus graus de pertinência na perspectiva do sistema econômico. É no bojo desse processo que o sistema econômico passa a redefinir as formas de conceber as relações entre as necessidades do sistema produtivo e a formação dos trabalhadores. Compreendendo diferentes interpretações do modelo taylorista-fordista de organização do trabalho, a empresa contemporânea propõe uma redefinição dos atributos necessários aos trabalhadores que tem sido designada, em contraposição ao treinamento especializado, de formação do "trabalhador polivalente".

Desse modo, transformações no sistema produtivo e no mercado de trabalho têm profundos impactos sobre as diretrizes educacionais da formação profissional e recaem com grande pressão sobre os trabalhadores e as novas gerações que pleiteiam lugares nesse mercado que define seus requisitos em termos de qualidades, atributos e recursos individuais para certas habilidades específicas necessárias em situações bem delimitadas; em uma palavra, em termos de competências. O impacto por certo refere-se aos modos como o sistema de ensino instalado, que inclui, tradicionalmente, a formação profissional especializada, relaciona-se com os novos requisitos do mercado. Contudo, um dos aspectos mais importantes do processo é o deslocamento institucional das atividades educativas. Desafiando o monopólio da escola como lugar especializado de aprendizagem e formação, a empresa passa a incorporar as atividades de qualificação profissional, tendendo assim a constituir-se em novos centros especializados de aprendizagem e treinamento, com uma capacidade de expansão e desenvolvimento da qual a Hamburger 
University da empresa alimentícia McDonald's é representante exemplar ${ }^{1}$.

b) Segundo a teoria política clássica, a crise da esfera pública é uma velha questão para a sociedade moderna às voltas, desde sua institucionalização, com os dilemas gerados por uma esfera pública concebida a partir de relações privadas. Se a questão é bastante antiga, a forma que toma na atualidade tem, certamente, suas especificidades. A crise do déficit público define a necessidade da atual reforma da universidade que se insere, assim, no contexto mais amplo da própria reforma do estado. Ligada à reestruturação do modo capitalista de produção a partir da revolução tecnológica que se inicia nos anos 70, a atual reforma do estado insere-se num amplo processo de redefinição das relações entre estado, economia e sociedade, ou seja, redefinição das fronteiras e das tensões entre as dimensões pública e privada na modernidade contemporânea.

Uma das tendências presentes nessa redefinição refere-se ao encolhimento da dimensão pública do estado nacional tal como ela se constituiu como fruto de lutas sociais que, organizadas em torno de identidades coletivas, reconfiguraram o estado liberal clássico enquanto estado do bem estar social no século XX. Nessa forma, o estado expandiu-se e abarcou diversos setores sociais como habitação, educação, saúde, cultura e comunicações. A concepção é de um estado responsável pelo interesse público que atua na direção do controle das conseqüências sociais do funcionamento da lógica pura do mercado, isto é, das relações sociais em termos de contratos privados entre indivíduos. Tendo sido decretada a falência - colapso financeiro - do estado previdência, o estado atualmente retira-se de todo esse conjunto de setores da vida social redesenhando as tensões entre as esferas pública e privada na modernidade. O processo concretiza-se por meio da definição de "setores de serviços não exclusivos do estado" abrindo espaço, de um lado, para a expansão da esfera privada nas áreas dos serviços públicos e, de outro, para a constituição de uma "esfera pública nãoestatal", âmbito da atuação das organizações sociais, forma institucional que se situa entre, de um lado, a empresa privada e a busca do lucro particular e, de outro, o órgão público e a perspectiva do bem comum.

As dimensões sociais e políticas que circundam a questão da universidade constituindo-a em suas especificidades contemporâneas permitem, então, considerar dois processos concernentes à crise da universidade pública. Ligada especialmente à reconfiguração das esferas pública e privada, tem-se a expansão da rede privada de ensino e o correlato desmantelamento da rede pública de instituições educativas. Mas, intimamente vinculada aos processos em curso no âmbito do mundo do trabalho, a crise da universidade pública configura-se como crise do público no próprio interior das instituições públicas de ensino superior. Para dar conta minimamente desse aspecto da questão é preciso considerar a história das relações e progressiva aproximação entre o sistema educativo e o mercado de trabalho na modernidade. De fato, a questão remete a uma tensão histórica da universidade moderna, composta pelas relações entre a tarefa da formação cultural e a da qualificação profissional especializada. Em seu cerne localiza-se a questão da autonomia do trabalho intelectual, que se conforma de modos diversos de acordo com as especificidades das diferentes áreas de conhecimento.

\footnotetext{
"A Universidade do Hambúrguer, que fica no centro do campus do McDonald's em Oak Brook, nos arredores de Chicago, treinou mais de 65.000 'bacharéis em hamburguerologia' desde que sua primeira aula ocorreu em 1961 (...)" (The economist, 1999). Agradeço a Leopoldo Waizbort a indicação dessa matéria.
} 
Segundo a sociologia do conhecimento e a história das ciências e das instituições científicas e culturais, a universidade moderna corresponde à institucionalização das condições de possibilidade do trabalho intelectual autônomo. De acordo com o sociólogo Pierre Bourdieu $(1974,1981)$, a autonomia dos campos científicos é fruto da invenção histórica de um contrapoder crítico aos poderes religiosos, econômicos e políticos. A lei fundamental desse microcosmoé a rejeição dos valores e objetivos da economia e da política, respectivamente, a riqueza e o poder, funcionando por um tipo específico de troca que define a forma da competição por argumento, demonstração e raciocínio tendo em vista a busca da razão e da verdade (cf. também Charle, 1994 e Charle \& Verger, 1994).

É somente quando os campos de produção cultural atingem alto grau de autonomia que gestam o intelectual moderno e sua política da pureza ou política anti-política pela qual não somente defende a pureza de seu campo autônomo como propõe a extensão de seus valores para a orientação da vida social, política e ética da coletividade. Com base em uma autoridade conquistada em função de uma competência específica, o intelectual moderno transgride os valores mais intocáveis da sociedade e da cultura, como Émile Zola atingiu o nacionalismo e o patriotismo ao defender Richard Dreyfus, "o traidor da França". A transgressão projeta-se assim como uma das tarefas do intelectual moderno, esse produto histórico da autonomia dos campos de produção intelectual caracterizado, nos termos de Bourdieu, pela liberdade em relação aos poderes, a crítica das idéias prontas, a demolição das alternativas simplistas e a restauração da complexidade dos problemas.

A partir de outras referências, o filósofo José Arthur Giannotti (1998) define a universidade como poder acadêmico, ou seja, uma forma de poder e de hierarquia baseada no mérito intelectual que tem a auto-suficiência como condição do cumprimento de suas finalidades específicas. Isso implica a gestão autônoma de seus recursos, independentemente da origem. Enquanto poder acadêmico, a universidade recusa toda ingerência externa sobre o pensamento e a investigação. Através dela, a modernidade revoluciona o modo de se relacionar com a tradição - não se trata mais somente de transmiti-la, mas de repensá-la pela raiz. Em outras palavras, não se trata somente de reproduzir a cultura, mas de produzir cultura por meio da reflexão crítica do existente. Nesse sentido, o cerne do significado civilizacional da universidade não aponta para a qualificação profissional mas para a institucionalização das condições de possibilidade de produção e reprodução de uma força social capaz de se renovar e se repensar.

Em suma, a universidade define-se por um poder acadêmico exercido por um corpo de professores e pesquisadores, incluindo os alunos, capazes de autodisciplinar-se para conhecer, conhecer-se e pensar o conhecimento que herdam e legam. Definindo assim a formação como tarefa primeira da universidade, Giannotti afirma a necessidade da defesa da universidade pública, já que a universidade particular tende a não conseguir cumprir os requisitos dos quais depende a constituição do poder acadêmico e conseqüentemente o desempenho da tarefa de formação. Para o filósofo, perder de vista o ideal de formação acadêmica põe em risco os vínculos da sociedade brasileira com a civilização oci- 
dental. Segundo ele, a constituição da universidade como poder acadêmico não se reduz ao problema da eficácia na obtenção de um recurso isolado mas diz respeito a uma forma de sociabilidade, ao sentido da civilização. A pergunta, portanto, é se estamos dispostos a pagar por essa específica forma de vida.

Segundo Giannotti, na modernidade a associação da universidade com o capitalismo define uma segunda tarefa institucional. A necessidade de legitimação social da instituição universitária exige de sua parte algum compromisso com projetos sociais tais como, por exemplo, o desenvolvimento econômico. O ponto a enfatizar aqui é o modo como se introduz, assim, uma tensão de base na instituição acadêmica que passa a definir-se simultaneamente como produtora e reprodutora de cultura, duplicando, em seu interior, contradições básicas do projeto moderno de uma sociedade secular, livre e igualitária. Usando os termos de Franklin Leopoldo e Silva (1999), trata-se da questão das tensões entre a universidade como produto histórico e a universidade como instância crítica do movimento histórico. Tensões que se instalam de modo diverso entre as diferentes áreas do conhecimento devido às especificidades dos saberes e às funções que exercem nos sistemas sociais. Por isso, as complexas relações entre a sociedade moderna e a racionalidade científica compreendem duas dimensões complementares que se vinculam essencialmente de forma mediada, dado o próprio princípio de autonomia e auto-regulação inscrito nos métodos de investigação racional da realidade:

a) externamente - os usos sociais da ciência, isto é, as funções práticas socialmente atribuídas aos conhecimentos científicos, marcadamente as funções de produção e reprodução dos sistemas econômico e político;

b) internamente - os consensos e divergências em campos científicos e culturais específicos acerca dos perfis disciplinares, teóricos metodológicos, em suas relações com os modos de conceber a natureza e os objetivos da racionalidade científica na modernidade.

Como sustenta a sociologia das ciências de Pierre Bourdieu (1997), a independência e descompromisso são o critério último para a avaliação do grau de autonomia alcançado pelas diversas disciplinas científicas ao longo do desenvolvimento. A autonomia se expressa no modo como as disciplinas traduzem as demandas sociais em seus próprios termos, incorporando pressões externas de forma profundamente mediada de modo que nas áreas mais autônomas as demandas externas tendem a tornar-se irreconhecíveis tal a diferença entre a formulação social da demanda e sua tradução nos termos próprios a um campo específico de saber. Ao contrário, a incorporação de demandas externas de forma imediata nos termos postos por diversas frações sociais indica o baixo grau de autonomia conquistado por uma certa área de produção intelectual.

As ciências exatas e naturais travaram suas maiores lutas por autonomia há alguns séculos e desfrutam, na atualidade, dos mais altos níveis de autonomia que se manifestam no reconhecimento social da distinção entre produção científica e usos sociais desses conhecimentos. Embora a II Guerra tenha instalado a questão dos usos sociais da ciência e a questão da ética na ciência no centro do debate científico de forma dramática não se pode dizer que tenha ocorrido uma transformação radical no modo como a sociedade concebe a inde- 
${ }^{2} \mathrm{O}$ que não significa que não ocorram equívocos, desencontros e desentendimentos na relação entre as ciências e a sociedade. Ver, por exemplo, a análise do caso do estudo encomendado aos médicos pelo Congresso norteamericano para fundamentar decisões legislativas sobre o cigarro (cf. Barnes, 1980). pendência e o descompromisso dos cientistas em relação às apropriações sociais dos conhecimentos que produzem ${ }^{2}$. Comparativamente, as humanidades não chegaram ainda a conquistar esse nível de autonomia e há poucos indícios de que o problema seja sanado com o progressivo desenvolvimento das disciplinas que compõem essa área do conhecimento. A questão é tão antiga quanto as próprias ciências humanas cujas histórias são marcadas pela influência do modelo epistemológico e metodológico das ciências naturais, vale dizer, o modelo do método experimental. Desde Durkheim e Weber, a sociologia constata as dificuldades de reconhecimento de uma ciência cujo objeto é o seu próprio mundo, do qual todos os seus membros consideram-se conhecedores. As expectativas vindas de diferentes lugares sociais exigem ora mais ora menos do que uma disciplina científica estaria apta a oferecer, oscilando entre suspeitas de particularismos, demandas de liderança moral e política ou de produção de tecnologias de administração e controle social. Mas isto é ainda uma simplificação quando se considera que a questão da natureza e dos objetivos da sociologia é um tópico interno ao campo tão antigo quanto a própria disciplina, cuja história é marcada por debates internos, definidores de escolas e perspectivas divergentes, em torno das concepções de ciência e de humanidades.

Para aprofundar o problema, parece-me que um passo inicial obrigatório é considerar a história do debate em torno do perfil intelectual da disciplina, da profissionalização do sociólogo e das funções sociais dos conhecimentos sociológicos, tal como se configura a partir da década de 30 deste século e do extraordinário desenvolvimento da sociologia norte-americana. Dois condicionantes fundamentais desse desenvolvimento são:

1. a inesperada vitória eleitoral de Roosevelt que, sem ligações político-partidárias importantes, "corre por fora" fazendo sua campanha presidencial pelo rádio. Sua vitória corresponde, assim, ao descobrimento das potencialidades políticas dos meios de comunicação de massa que condiciona a enorme expansão das pesquisas de opinião.

2. a emergência de um estado que se incumbe de coordenar e planejar a economia visando o controle das forças que operam estritamente segundo a lógica do mercado. O estado como agente da planificação centralizada por certo passa a exigir um grande corpo de especialistas e técnicos que coletem, sistematizem e analisem dados macroeconômicos para orientar o planejamento. A concepção da política como atividade de argumentação e mobilização da vontade e da ação dos grupos sociais - politics - perde espaço com a expansão da idéia da política como atividade de administração, tecnicamente orientada, de problemas sociais bem delimitados com base em dados científicos que orientam a escolha entre as alternativas de solução - policy making. Define-se assim um processo de alinhamento da universidade ao sistema político financiado especialmente por fundações privadas, na tradição das associações filantrópicas puritanas. Trata-se de fomentar a produção de dados e 
pesquisas empíricas úteis à administração política e econômica.

É esse contexto que abriga o trabalho do sociólogo austríaco Paul F. Lazarsfeld, orientado para o desenvolvimento de métodos quantitativos de coleta e tratamento de dados para grandes populações e do survey enquanto instrumento essencial para a sondagem das preferências individuais. Tratava-se, então, nas palavras de Lazarsfeld, de emancipar de uma vez por todas a sociologia da filosofia e formar os "especialistas da gestão racional", da administração e do marketing (cf. Adorno, 1973 e Pollak, 1979). A sociologia empírica separase da teoria universitária e da pesquisa qualitativa da Escola de Chicago e reorganiza a produção sociológica em equipes hierarquizadas que dividem o trabalho segundo a especialização de seus membros, em moldes adequados a uma "empresa de investigação administrativa", para usar a expressão de Lazarsfeld.

Um ponto essencial a destacar no desenvolvimento histórico da profissionalização e da especialização sociológicas é a divisão do trabalho entre teoria, metodologia e pesquisa empírica. Nesse âmbito, a atuação de Parsons na Universidade de Harvard aparece como complementar à atuação de Lazarsfeld definindo dois grandes campos da sociologia. De um lado, a pesquisa empiricamente delimitada, produtora de dados e, de outro, a sistematização, em registro funcionalista, dos pressupostos e resultados da base empírica disciplinar, criadora de teoria.

Atendendo a uma crescente demanda social, a sociologia produzida no Bureau of Applied Social Research de Paul Lazarsfeld na Columbia University atrai muitos estudantes interessados na profissionalização em uma área emergente. Na acirrada concorrência entre as universidades norte-americanas, Columbia impõe-se como o modelo da concepção moderna de sociologia enquanto os contratos de pesquisa do Bureau aumentam o orçamento universitário de Columbia. Conselheiro da Fundação Ford desde 1951, Lazarsfeld é um dos mentores do projeto norte-americano de modernização intelectual e ideológica da sociologia européia. Ao final dos anos 60, a reforma institucional e curricular modernizadora está implantada em toda a Europa e domina a produção sociológica internacional demarcando os trinta anos de hegemonia da escola de Columbia, os rumos da profissionalização da sociologia e de suas funções práticas nas esferas da política e da economia.

As primeiras críticas ao modelo de Columbia surgem de membros da escola de Chicago que marcam a formação e a produção sociológica norteamericana ao longo dos anos 20 com sua pesquisa de campo qualitativa. Com a Guerra, o Bureau passa a receber intelectuais europeus de perfil marcadamente distinto do de Lazarsfeld, como os membros da escola de Frankfurt, formados na tradição filosófica alemã, Theodor Adorno e Herbert Marcuse. As divergências intelectuais e políticas entre Lazarsfeld e Adorno ilustram exemplarmente o conflito entre dois perfis intelectuais e duas concepções de sociologia, delineando o cisma disciplinar entre a crítica social e o empirismo: de um lado, segundo a concepção tradicional de cultura, o intelectual erudito que faz uma sociologia voltada para produção de novas interpretações teóricas; de outro, conforme a diretriz que se define como a concepção moderna de ciên- 
cia, o pesquisador especializado que produz uma sociologia voltada para a produção de dados e informações.

Em meados do século, o debate em torno do perfil da produção sociológica torna-se mais acirrado em análises que vinculam estreitamente os aspectos políticos, organizacionais e cognitivos da prática sociológica no século XX. Assim, um tópico essencial da discussão refere-se aos condicionantes externos da produção sociológica, isto é, à análise dos vínculos entre a sociologia e os sistemas político e econômico e seus efeitos sobre o processo de profissionalização da ciência social (cf. Fernandes, 1980 e Nicolaus, 1982). A questão das relações entre saber e poder não se limita, então, à consideração das funções da sociologia para a reprodução dos sistemas sociais. Ela desdobra-se no âmbito da discussão teórica e metodológica atingindo os pressupostos dos métodos e técnicas da pesquisa empírica quantitativa, o empirismo e o positivismo (cf., por exemplo, Nisbet, s. d., 1970, 1986). A "virada reflexiva" é uma forma sintética de caracterização desse processo.

A ciência torna-se reflexiva quando suspende a "relação normal" entre sujeito e objeto e, em seu lugar, o sujeito epistêmico, voltando-se para si mesmo, analisa sua relação consigo mesmo como sujeito empírico, com os instrumentos de trabalho que utiliza, com a comunidade científica de que faz parte e, em um último nível, com a sociedade de que é membro (cf. Santos, 1989). Em suma, quando a investigação parte do foco sobre o próprio sujeito da investigação e suas práticas concretas no processo de produção de conhecimento, colocando no cerne da reflexão metodológica o tema das relações entre sujeito e objeto, isto é, entre pesquisador e informantes.

A "relação normal" entre sujeito e objeto refere-se à ênfase que a concepção epistemológica positivista concede ao objeto, complementar à idéia da neutralidade dos pressupostos e dos processos de investigação de tipo científico, ou seja, a neutralidade do sujeito do conhecimento. Para indicar de modo sucinto aonde se baseia o objetivismo positivista, penso que é suficiente identificar a idéia da certeza sensória que, de modos diversos, suporta tanto o fenomenalismo como o fisicalismo, sustentando que o fundamento dos conhecimentos científicos reside nas evidências da percepção dos sentidos e possibilitando uma distinção clara entre observação e interpretação ou, nos termos consagrados, entre fatos e valores. Com uma concepção da observação como um processo natural pelo qual a natureza revela-se, mostra a sua verdade aos seres humanos graças ao aparelho sensório universal de que eles são naturalmente dotados, pode-se fundar, como disse Durkheim, o edifício das ciências sobre a rocha sólida dos fatos, istoé, fenômenos que se dão a uma observação que é universal, partilhada por todos os seres humanos, constituindo as evidências sensórias em torno das quais não há divergências, mas um acordo naturalmente fundado.

A virada de foco para o primeiro termo da relação, isto é, para o próprio sujeito do conhecimento constitui-se em um amplo e complexo processo de crítica a essas idéias de modo que se pode dizer que a ampliação e o aprofundamento da reflexividade no pensamento sociológico recente decorre da crise da ortodoxia positivista que se inicia na primeira metade do século mas 
que se torna efetivamente visível na segunda metade, tendo como marco principal o fim da Segunda Guerra Mundial. Nesse sentido, a tendência geral à reflexividade delineia-se a partir do diagnóstico das relações entre ciência e sociedade na modernidade desenvolvendo-se contra o predomínio da metodologia formal e do empirismo. Enquanto um amplo processo de crítica da sociedade moderna que dá visibilidade aos limites e perversões da civilização ocidental em relação a seus princípios e objetivos, ela aponta para a vinculação teórica entre cultura e política, ambas entendidas como campos de práticas, espaços dinâmicos que se constituem e reconstituem continuamente pela ação de sujeitos sociais inseridos em experiências concretas ${ }^{3}$. A crítica à divisão de trabalho entre teóricos que pensam logicamente e pesquisadores que acumulam dados empíricos acompanha a proposição de uma abordagem sociológica das práticas disciplinares capaz de considerá-las enquanto relação social, levando a um desenvolvimento marcante dos métodos e técnicas qualitativos de pesquisa.

Nesse movimento de voltar-se para si mesmo, Boaventura de Souza Santos (1989) distingue duas grandes linhas de orientação. Uma delas, designada subjetivista, enfatiza o questionamento do sujeito epistêmico em confronto com o sujeito empírico, tendo em vista explicitar os valores, os préjuízos, as preferências, ou seja, as dimensões subjetivas que limitam a objetividade do conhecimento que produzem. Para muitos analistas, Wright Mills é o grande precursor dessa linha e Howard Becker $(1977,1993)$ seu maior representante na atualidade. O ponto essencial nessa perspectiva é a busca de controle da subjetividade pelo reconhecimento dela e a identificação dos limites da objetividade. Explicitar os próprios valores é o primeiro passo para o controle da validade científica da pesquisa sociológica de modo que só haverá objetividade se houver reconhecimento da subjetividade.

A segunda linha reflexiva, designada objetivista, é, em comparação com a primeira, mais impessoal. Ao invés de privilegiar o questionamento dos próprios valores, em um movimento de auto-análise do sujeito do conhecimento, a vertente enfatiza a necessidade de análise crítica dos instrumentos de investigação e do contexto social e institucional da prática científica, isto é, as condições sociais dessa prática e portanto da constituição de comunidades científicas e campos científicos. A proposta de Pierre Bourdieu de crítica epistemológica da prática sociológica exemplifica uma linha de trabalho que busca o conhecimento do erro e dos mecanismos que os engendram (cf. Bourdieu, Passeron \& Chamboredon, 1994). Por isso, a vigilância epistemológica, baseada no racionalismo aplicado de Gaston Bachelard, compreende uma psicanálise do espírito científico e uma sociologia do conhecimento. Com esses dois enfoques, ela constitui-se como o exame das condições e limites de validade de toda operação, técnica e conceitual, em função de cada investigação particular. Com a análise crítica de todos os instrumentos disponíveis, orientada pela concepção antiempiricista de toda técnica e todo método como teorias em ato, Bourdieu desenha um caminho que se propõe como a superação do dilema gerado pelas críticas aos condicionantes sociais e políticos da pesquisa sociológica, em termos tais que levam ao diagnóstico da total impossibilidade de fazer sociologia sem estar servindo ao poder político-econômico. Em um
Para uma pequena análise dessa reapropriação analítica da problemática do sujeito e da ação social na produção acadêmica brasileira cf. Garcia (1996). 
registro teórico diverso, esse problemaé um dos pontos de partida essenciais da crítica de Michel Thiollent (1980) à produção sociológica nos anos 60 que define sua proposta de pesquisa-ação, representando, assim, a vertente da pesquisa participante, importante linha de investigação sociológica entre os decênios de $60 \mathrm{e}$ $80^{4}$. De maneira geral, o ponto fundamental da perspectiva reflexiva objetivistaé o reconhecimento da subjetividade e a construção de procedimentos capazes de promover sua objetivação no âmbito teórico.

De certa forma, a classificação de Boaventura repõe o debate acerca do perfil disciplinar, historicamente oscilante entre a diretriz científica e o caráter humanístico, no próprio interior da perspectiva reflexiva. De todo modo, é possível observar que se a teoria social caminha na direção da perspectiva reflexiva, a pesquisa social expande-se extraordinariamente nos institutos de pesquisa de opinião ou de preferências individuais, em especial na forma de prévias eleitorais ou da pesquisa de mercado. Para além da constatação da distância entre a sociologia acadêmica e a pesquisa social empírica, deve-se notar que enquanto a ciência social - e a ciência em geral - direciona-se para o aprofundamento da crítica à noção da racionalidade em termos estritamente instrumentais, no âmbito da realidade econômico-social, a perspectiva técnico-instrumental desenvolve-se e expande-se entre os poucos redutos que haviam até agora se furtado ao seu predomínio. Dessa perspectiva, nada indica que a reflexão autocrítica da ciência esteja sendo complementada por práticas sociais capazes de sustentar uma concepção ampliada de racionalidade que significaria, então, uma profunda reformulação da própria ciência e da própria modernidade.

${ }^{4}$ Para uma importante referência brasileira, cf. Brandão (1984).
Para delinear a questão da autonomia acadêmica no campo cultural brasileiro, a referência histórica fundamental é a concepção do trabalho intelectual tal como se definiu na experiência da primeira geração de estudiosos formados na Faculdade de Filosofia, Ciências e Letras da USP nos termos de uma "intelectualidade pura". Limito-me aqui a recuperar a idéia central da concepção da autonomia cultural em Antonio Candido e em Florestan Fernandes. Em meu entender, Florestan Fernandes apropria-se da concepção de Antonio Candido acerca do perfil da nova geração acadêmica definido nos termos do intelectual moderno que, por meio do senso crítico adquirido no exercício de uma competência específica, conquista as condições de realização de uma crítica socialmente abrangente porque independente. Ao relacionar cultura e política em uma formulação interna aos campos da ciência e da arte, Antonio Candido delineia as possibilidades de uma crítica radical da coletividade e, assim, os contornos do papel de liderança social da intelectualidade que tem alcance político na medida em que se nega como ação política direta, tendendo a uma perspectiva politicamente radical como resultado da fidelidade aos valores e critérios específicos de seus campos, definidos pela crítica racional e pela busca da verdade e da beleza.

Florestan Fernandes apropria-se dessa concepção do intelectual moderno, em uma formulação própria, mais racionalista e sociológica, de crítica 
científica da sociedade. Aderindo a uma posição cientificista, Florestan afirma a autonomia da ciência em relação às esferas da ação, não para separar o pensamento da prática, mas em nome de uma prática orientada pela explicação - por definição, teórica - da dinâmica social. Enquanto instrumento de esclarecimento das descontinuidades entre as possibilidades da ordem social e a ação dos agentes sociais, a sociologia dispõe-se a direcionar a práxis pelo controle racional dos aspectos irracionais que obstaculizam o pleno desenvolvimento da emancipação possível. É nesse sentido que sua concepção da sociologia como ciência empírico-indutiva incorpora a questão da educação, situando a contínua preocupação do autor com os perfis dos cursos de ciências sociais e as perspectivas de desenvolvimento da sociologia científica no Brasil. O ponto básico a reter é a centralidade conferida à autonomia da razão científica e à correlata independência da universidade - que por isso deve ser pública - como centro de produção e reprodução do pensamento racional. Na associação entre ciência e sociedade, a primeira detém o papel dinamizador e é em seus termos que devem ser traduzidas as demandas externas. É por isso que Florestan desenvolve o tema da relação entre teoria e prática de uma perspectiva interna ao campo da sociologia, como sociologia aplicada. O cumprimento das finalidades sociais da ciência exige, portanto, que a universidade, núcleo da criação científica, mantenha-se em descompasso com a realidade social imediata. Ela não pode estar totalmente adaptada à sociedade, tampouco completamente entrosada ao processo histórico, só podendo realizar suas tarefas na medida em que mantém algum deslocamento em relação ao seu próprio tempo.

Levando em conta, então, que o desajuste em relação às determinações do presente consta, na história institucional, como uma determinação de origem, por certo diferencialmente assumida pelas diversas escolas e faculdades como "a marca da USP", as propostas de reformas universitárias modernizadoras, que se iniciam na década de 60 , surgem com o sentido de propostas de ajustamento da instituição ao seu tempo histórico, redefinindo as formas da tensão entre as tarefas de formação e de qualificação profissional (cf. Fernandes, 1975, 1984; Cunha, 1988; e Cardoso, 1982, 1985, 1987, 1989, 1998).

Para expor um único exemplo, retomo sucintamente a análise de Franklin Leopoldo e Silva (1999) do relatório de 1986 do grupo Geres - Grupo Executivo para a Reformulação do Ensino Superior - do MEC. Não se trata de reconstruir os debates em torno das diversas reformas mas apenas de sustentar minimamente a idéia de que a discussão atual está inserida em uma longa história cujo conhecimento é requisito para o entendimento da forma atual da questão, inclusive de suas especificidades. De fato, um dos problemas que está posto para a análise das mudanças atuais refere-se à natureza dos processos que as engendram e se representam novas configurações estruturais ou aprofundamentos e desenvolvimentos de processos anteriormente estabelecidos.

No relatório do Geres de 1986, a avaliação e a modernização são apresentadas como os critérios fundamentais para a análise da questão da universidade. Franklin Leopoldo e Silva aponta a lógica da eficiência que subjaz a esses critérios e sua natureza excludente em relação a toda resistência à sua aceitação 
como padrão único para o juízo acerca do trabalho universitário. O autor reconstrói o caminho pelo qual essa concepção vincula avaliação financeira e avaliação de desempenho institucional por uma operação de extensão semântico-operatória do conceito de controle, visto que o controle do uso dos recursos universitários já estava previsto na legislação. O relatório argumenta que uma avaliação limitada ao controle dos meios não passa de um ritual burocrático se não se liga à avaliação dos fins a qual se concretiza por meio de políticas educacionais voltadas para a projeção do desempenho. Denominada controle social da instituição, ela seria essencialmente justa já que a universidade é financiada pela sociedade por meio dos impostos. Frente a ela, a reivindicação de autonomia não pode implicar o isolamento da universidade em relação à sociedade e às necessidades sociais que esta espera ver atendidas como retorno ao seu investimento na educação superior.

Segundo Leopoldo e Silva, é certo que a universidade é uma instituição social e como tal tem seu sentido construído na interação com a sociedade. O problema é como se entende essa relação. Como já se viu, pode-se entender que a relação entre universidade e sociedade se estabelece por via da preservação do caráter autárquico da instituição cujo sentido aponta não para a desvinculação entre meios e fins mas para a ligação orgânica entre auto-suficiência e finalidades próprias. Isto é, a finalidade da universidade só se alcança $n a$ e pela auto-suficiência. Dessa concepção decorre que o atendimento das demandas sociais se faz de forma mediada, passando pela elaboração autônoma das formas de relacionamento indireto com a sociedade e com o estado. Conforme outra concepção, contudo, a relação é direta e imediata. A imediatez supõe a definição concreta das necessidades sociais, o que é realizado pela instância que as interpreta e coordena assim como às expectativas de atendimento, vale dizer, o estado e os governos e suas diretrizes orientadoras de prioridades para a alocação de recursos para o sistema de ensino e pesquisa. É nesse movimento que se concebe o controle dos fins da universidade - para além do controle do uso dos meios - definidos em função de metas pré-fixadas a partir de macrocritérios ligados a uma determinada visão de desenvolvimento nacional. Nesse quadro, a auto-suficiência recua e a autonomia passa a significar, no máximo, a escolha da melhor forma de adequação aos parâmetros da lógica da eficiência institucional que se define pela eficácia com que a instituição realiza os fins projetados. $\mathrm{O}$ espaço das mediações que permitia à universidade a inserção crítica em termos de julgamento e atendimento de demandas sociais desaparece.

$O$ atual debate em torno da questão da universidade insere-se completamente na perspectiva da modernização, tendo por dimensões essenciais, em meu entender, a avaliação institucional e um modelo pedagógico fundado no princípio de "aprender a aprender". A avaliação institucional quer designar um momento da história universitária caracterizado pela concepção da academia enquanto estrutura de gestão e arbitragem de contratos, segundo as diretrizes essenciais do chamado novo paradigma de gerência social (cf. BID, s. d.; Cohen \& Franco, 1993; Kliksberg, 1996; e Arruda, 1999). Concebida para fazer frente ao esgotamento da capacidade do estado de suprir as necessidades sociais, a nova gerência deve estar habilitada a administrar situações de escassez, gerir a 
complexidade dos recursos tecnológicos e enfrentar a competitividade mundial. Para isso, ela precisa ter como característica essencial a flexibilidade, isto é, a capacidade de adaptação estratégica a múltiplos ambientes e cenários, a ser continuamente avaliada por processos de monitoramento da execução dos programas, incluindo a avaliação dos resultados pelos usuários (accountability). Desse modo, a principal tarefa da gerência social é a facilitação de processos de mudança para o que precisa ser capaz de criar uma cultura de compromisso e colaboração entre todos os agentes envolvidos em cada programa tendo em vista, sobretudo, o alinhamento de propósitos.

Nas análises da aplicação do modelo de gerência social à administração universitária é recorrente o diagnóstico de uma tensão fundamental: o modelo organizacional pressuposto nos processos de avaliação institucional tem princípios que conflitam frontalmente com os objetivos específicos da universidade (cf. Le Monde, 1997; Chauí, 1998; e Cardoso, 1999). O ponto básico é que o modelo organizacional pressupõe um tipo de organização que se define por um projeto homogêneo e coerente, baseado no consenso de propósitos e finalidades. Nas palavras de Marilyn Strathern, "a avaliação institucional mede a instituição enquanto uma organização de acordo com critérios predeterminados que definem como deve ser uma organização eficiente" (Strathern, 1999, p. 22). Assim, o princípio do monitoramento institucional atinge o âmago da concepção tradicional da universidade como instituição que abriga tensões e perspectivas conflitantes segundo a própria lógica do princípio primeiro de liberdade de investigação, comportando metas não apenas diversas, mas divergentes e conflitantes entre si. É de fato notável que os processos de avaliação acadêmica não se iniciem com pesquisas exploratórias sobre os modos como efetivamente funcionam universidades específicas. O fato autoriza a interpretação de que o objetivo da avaliação nãoé produzir um modelo específico do funcionamento da organização universitária, mas reorganizar a instituição nos moldes de um modelo organizacional pré-definido segundo uma concepção determinada da eficiência de sistemas-peritos para a realização de objetivos e a obtenção de resultados.

Uma outra idéia fundamental na análise de Stratherné que os significados expandem-se a partir de uma fonte e retornam posteriormente a ela ressignificados pelos outros contextos nos quais foram inseridos. Com base nessa perspectiva antropológica de apropriação cultural, a autora mostra como foi a área da educação que ensinou as empresas a combinarem avaliação de recursos financeiros e humanos. O momento atual seria, então, próprio ao segundo retorno da idéia de avaliação, criada na área da educação e apropriada pela administração empresarial. No primeiro retorno, os procedimentos padronizados de auditoria tornam-se rotina na avaliação financeira da universidade - o monitoramento do uso dos recursos investidos na instituição. Nos últimos vinte anos, a contabilidade une-se à idéia de responsabilidade (accountability) gerando uma expansão descontrolada dos domínios da avaliação que atinge, como se viu, as próprias finalidades acadêmicas. Essas considerações apontam para a questão das referências científicas do modelo de gestão social e administração institucional. Para localizála brevemente é preciso considerar o modelo pedagógico inscrito nas propostas 
atuais de reformulação organizacional da academia e, de modo geral, dos sistemas de ensino. A noção essencial aqui é o princípio de "aprender a aprender" e de transferir habilidades de um domínio a outro.

Um dos tópicos mais reiterados nos diagnósticos do esgotamento histórico da concepção tradicional da universidade é a crítica à especialização dos saberes associada à notável valorização da chamada formação interdisciplinar. Nesse sentido, a concepção até então predominante da educação, em todos os seus níveis, como esfera de ensino de conhecimentos e saberes organizados em disciplinas tende a ser substituída pela noção de educação como esfera de aprendizagem de habilidades específicas, centralizada na figura do estudante como sujeito individual de sua própria formação. A difusão das noções de desempenho, eficiência e, especialmente, competências é uma das expressões mais visíveis dessa tendência geral. Por meio da análise dos sentidos que lhes são atribuídos pode-se apontar alguns traços gerais dessa tendência que marca a história contemporânea da educação na modernidade.

Como mostram as investigações coordenadas por Françoise Ropé e Lucie Tanguy (1997), um traço básico da noção de competência é que ela é inseparável da ação, constituindo-se assim como um atributo que só pode ser realmente avaliado no exercício de tarefas específicas inseridas em situações concretas. É nessa perspectiva que o atual modelo pedagógico apropria-se de categorias criadas no âmbito das ciências cognitivas, da psicologia social e das teorias sociológicas da escolha racional sustentando o princípio do "aprender a aprender" e da transferência de habilidades em torno do trio saber, saber-fazer, saber-ser. Contudo, a expansão dos usos sociais dessas noções entre formadores, administradores e empresários tende a atribuir-lhes sentidos bem definidos, não problematizados, para além do que autorizam esses conceitos em suas áreas específicas de conhecimento. É fato que as ciências cognitivas redefiniram as noções de saberes e competências mas jamais forneceram modelos gerais para a transferência de competências entre diferentes domínios. Diferentemente, elas permitem afirmar que a transferência é possível entre situações próximas, inseridas em um mesmo domínio, mas é impossível entre domínios ou disciplinas diferentes, a não ser que seja precedida de intenso treinamento (cf. Ropé \& Tanguy, 1997, p. 202-203). Assim, como aponta Strathern, estamos diante de um paradoxo: ao estabelecer como objetivo a transferência de habilidades não se pode reproduzir aquilo que a torna efetiva, ou seja, o enraizamento em um contexto específico já que a habilidade de inserir-se em diversos contextos só se aprende em um contexto de cada vez (cf. Strathern, 1999, p. 31). Determinada pelos altos níveis de especialização da produção científica e cultural, a interdisciplinaridade tem como condição de possibilidade a formação avançada em uma área específica. Ela é algo que só se realiza nas etapas mais avançadas da produção cultural por grandes especialistas que exatamente porque dominam profundamente um campo específico, além de deter um conhecimento geral, sabem explorar e criar diálogos com outros campos em outras áreas, refletindo sobre suas relações.

Se assim é, as propostas de reformulação curricular dos cursos de 
graduação em formatos basicamente mais curtos, de 1 a 2 anos, e mais generalistas não podem ter por referência a educação científica e a formação cultural. Elas apontam, então, preferencialmente para a qualificação profissional nos termos definidos pelo mundo do trabalho. Cabe a esta altura lembrar que toda a discussão refere-se a uma universidade massificada, resultante da relativa democratização do acesso às instituições de ensino superior que determinou a desvalorização social dos diplomas universitários de bacharelado. Nesse contexto, o valor social dos diplomas torna-se muito variável e seus detentores devem provar que são efetivamente capazes de fazer uso de seus conhecimentos em situações estabelecidas. A empresa surge, assim, como a instância privilegiada de validação dessas capacidades em termos de competências, ou seja, habilidades específicas e transitórias posto que ligadas a ambientes singulares. Assim, os níveis básicos da formação acadêmica aproximam-se do mundo do trabalho na mesma medida em que se afastam do mundo da produção cultural auto-regulada. $\mathrm{O}$ processo manifesta-se, por exemplo, na intensificação das ligações entre escola e empresa na forma básica dos estágios. Anteriormente entendidos como atividades a serem realizadas no fim dos cursos, eles são atualmente antecipados para os primeiros anos definindo, desde o início, o perfil da formação segundo o princípio de "aprender a aprender", que então desdobra-se no princípio correlato do "aprender fazendo". Não parece despropositado, então, sugerir que o efeito dos cursos de curta duração no sistema de ensino superior até então definido sem controvérsia pela longa duração necessária à temporalidade própria ao trabalho intelectual, aponte muito menos para a transmissão de conhecimentos e a formação acadêmica e muito mais para a conformação de disposições psicológicas, fruto do monitoramento da experiência para a adaptação a um cenário instável definido pela reestruturação do sistema produtivo.

A centralidade conferida ao estudante como sujeito individual de sua própria aprendizagem aponta, por sua vez, para a individualização como um traço geral definidor do processo de mudança na esfera educativa. Também aqui é notável a similaridade com as transformações contemporâneas na esfera do trabalho. Assim como a flexibilização do mundo do trabalho é apresentada como uma transformação libertadora de forças criativas e emancipatórias do indivíduo, agora tornado empresário de si mesmo, os discursos da reforma universitária falam em nome da autonomia e da satisfação do aluno. A satisfação do aluno é uma nova finalidade da universidade que se equaciona com os dados da evasão escolar, coletados pela avaliação institucional. A lógica do raciocínio é que se há evasão é porque o aluno não está satisfeito. Trata-se então de atender melhor as suas expectativas visando a redução das taxas de evasão, índice da eficácia da organização no cumprimento de suas finalidades. Define-se, desse modo, a tarefa da instituição exclusivamente em termos de atendimento às demandas socialmente constituídas, comprometendo simultaneamente a autoregulação das disciplinas científicas e as condições de possibilidade da tarefa acadêmica de formação de uma força social essencialmente reflexiva, por meio da qual a universidade realiza-se como instância crítica do movimento histórico.

No âmbito da avaliação institucional, a padronização dos critérios 
e procedimentos avaliativos atende, basicamente, ao propósito de uma uniformização internacional que torne possível a medição e a comparação da eficácia dos sistemas de ensino, internamente hierarquizados, em nível mundial. No âmbito do modelo pedagógico, a avaliação configura-se como procedimento formativo porque constitutivo do próprio processo de aprendizagem. No registro da centralidade conferida ao aluno e suas expectativas em relação ao que a universidade pode lhe oferecer, ela tende a configurar-se segundo $o$ formato básico da pesquisa de opinião. Desconsiderando as críticas aos pressupostos teóricos das técnicas de aferição de preferências individuais, esses procedimentos têm por efeito reafirmar e reforçar o senso-comum entre os estudantes, na direção contrária ao estímulo ao pensamento informado e qualificado, requisito da formação de inteligências autônomas e reflexivas.

Em suma, as diretrizes da atual reforma universitária parecem encontrar sua expressão mais acabada no ensino técnico-profissionalizante, no qual o objetivo de aprendizagem de habilidades para a realização de tarefas específicas não tem que disputar espaço com o propósito tradicional de transmissão de um patrimônio cultural. Nesse sentido, elas apontam, em geral, para uma redefinição da histórica tensão entre as tarefas da formação cultural e da qualificação profissional que tende, no limite, a destruí-la enquanto tensão, por meio do esvaziamento de um de seus pólos, isto é, pela ausência de reprodução das condições de possibilidade da autonomia intelectual e da formação cultural no nível básico dos cursos de graduação.

Recebido para publicação em fevereiro/2000

UNITERMS:

university, social sciences, sociology of education.
ABSTRACT: The historical analysis of the social and intellectual processes that characterise the cultural and scientific education in contemporary modernity allows for the reconstruction of cultural and educational questions, which are perceived as academic and administrative problems in our daily lives at the university. The approach adopted in this paper is situated at the intersection between intellectual history, the sociology of science and scientific institutions and the sociology of education and culture. It discusses, firstly, the wide institutional processes - in the political, economic and cultural spheres - that circumscribe the contemporary questions of the university and the education in social sciences; secondly, it analyses some of the central aspects of the sociological debate on the nature of the discipline and the profile of the education in social sciences; finally it looks at a few premises and basic categories of the present proposals for the reform of the university.

GARCIA, Sylvia Gemignani. The question of the university and the education in social sciences. Tempo Social; Rev. Sociol. USP, S. Paulo, 12(1): 123-140, May 2000. 


\section{REFERÊNCIASBIBLIOGRÁFICAS}

Adorno, T. W. (1973) Experiencias científicas em Estados Unidos. In: . Consignas. Buenos Aires, Amorrortu, p. 107-140.

ArrudA, Maria Arminda do Nascimento. (1999) A nova política de pós-graduação no Brasil. Tempo Social, São Paulo, 11(2): 219-229, outubro.

BARNES, Barry. (1980) Sobre la recepción de las creencias científicas. In: (org.). Estudios sobre sociologia de la ciencia. Madrid, Alianza Editorial.

BECKER, Howard S. (1977) Uma teoria da ação coletiva. Rio de janeiro, Zahar. . (1993) Métodos de pesquisa em ciências sociais. São Paulo, Hucitec.

BID. (s.d.) Evaluación: una herramienta de gestión para mejorar el desempeño de los proyectos. BID-Oficina de evaluación, Washington, EUA.

Bourdieu, Pierre. (1974) Campo do poder, campo intelectual e habitus de classe. In: Miceli, Sergio (org.). A economia das trocas simbólicas. São Paulo, Perspectiva.

. (1981) The corporatism of the universal. Telos, Fall, (81): 99-110.

. (1997) Les usages sociaux de la science. Paris, INRA.

\& Passeron, J. C. \& Chamboredon, J. C. (1994) El oficio del sociólogo. Mexico, Madri, Siglo veintiuno editores, Siglo veintiuno de España editores.

Brandẽo, Carlos Rodrigues. (1984) Repensando a pesquisa participante. São Paulo, Brasiliense.

CArdoso, Irene. (1982) A universidade da comunhão paulista. São Paulo, Cortez. - (1985) A USP e o espírito de instituição. Revista de Política e Cultura, Presença, (5), janeiro.

. (1987) A universidade e o poder. Revista USP, São Paulo, (6), julho-setembro.

. (1989) A modernização da universidade brasileira e a questão da avaliação. In: MARTINS, C. B. (org.). Ensino superior brasileiro: transformações e perspectivas. São Paulo, Brasiliense.

. (1998) Maria Antônia: um estilo esquecido. In: MArTinEZ, Paulo (org.). Florestan ou o sentido das coisas. São Paulo, Boitempo editorial.

. (1999) O discurso da universidade. Tempo Social, São Paulo, 11(1): 49-65, maio.

Castells, Manuel. (1999) A sociedade em rede. A era da informação: economia, sociedade e cultura. Vol. 1. São Paulo, Paz e Terra.

Charle, Christophe. (1994) La république des universitaires. Paris, Seuil. \& Verger, Jacques. (1994) Histoire des universités. Paris, Presses Universitaires de France.

CHAứ, Marilena. (1998) A universidade hoje. Praga, São Paulo, (6), setembro. 
Cohen, Ernesto \& Franco, Rolando. (1993) Avaliação de projetos sociais. Rio de Janeiro, Vozes.

Cunha, Luis Antonio. (1988) A universidade reformada. São Paulo, Francisco Alves.

FERNANDES, Florestan. (1975) Universidade brasileira: reforma ou revolução. São Paulo, Alfa-Ômega. . (1980) A natureza sociológica da sociologia. São Paulo, Ática. (1984) A questão da USP. São Paulo, Brasiliense.

FREITAG, Michel. (1995) Le naufrage de l'université. Québec/Paris, Nuit blanche/ La découverte.

GARCIA, Sylvia Gemignani. (1996) Cultura, dominação e sujeitos sociais. Tempo Social, São Paulo, 8(2): 159-176, outubro.

Giannotti, José Arthur. (1998) Em defesa da universidade pública. Folha de S. Paulo, São Paulo, 17/04, p. 3-7.

KLIKSBERG, Bernardo. (1996) El pensamiento organizativo: de los dogmas a un nuevo paradigma gerencial. Tesis grupo editorial, Norma SA, Buenos Aires.

Le Monde de l'éducation, de la culture et de la formation. (1997) Université. Paris, (252), octobre.

Nicolaus, Martin. (1982) A organização profissional da sociologia: um enfoque a partir da base. In: BLACKBURN, Robin (org.). Ideologia na ciência social. Rio de Janeiro, Paz e Terra.

NisBet, Robert. (s. d.) La formácion del pensamiento sociológico. 2 V. Buenos Aires, Amorrortu.

. (1970) Sociology as an art form. In: Tradition and revolt, historical and sociological essays. New York, Vintage Books.

. (1986) Conservadorismo e sociologia. In: MARTins, José de Souza (org.). Introdução crítica à sociologia rural. São Paulo, Hucitec.

PollaK, Michael. (1979) Paul F. Lazarsfeld, fondateur d'une multinationale scientifique. Actes de la Recherche en Sciences Sociales, Paris, (25), janvier.

Ropé, Françoise \& TANGUY, Lucie (orgs.). (1997) Saberes e competências. $O$ uso de tais noções na escola e na empresa. Campinas, Papirus.

SANTos, Boaventura de Souza. (1989) Introdução a uma ciência pós-moderna. Rio de Janeiro, Graal.

SILVA, Franklin Leopoldo e. (1999) A experiência universitária entre dois liberalismos. Tempo Social, São Paulo, 11(1): 1-47, maio.

StRATHERn, Marilyn. (1999) Melhorar a classificação. A avaliação no sistema universitário britânico. Novos Estudos, São Paulo, (53), março.

The economist. (1999) The burger king. October, $23^{\text {rd }}$, p. 78.

Thiollent, Michel. (1980) Crítica metodológica, investigação social e enquete operária. São Paulo, Polis. 